\title{
ACÚMULO DE DEPOSIÇÃO DE LIXO EM AMBIENTES COSTEIROS: A PRAIA OCEÂNICA DE PIRATININGA - NITERÓI
}

\section{ACCUMULATION OFWASTE DISPOSALIN COASTAL ENVIRONMENTS: THE OCEAN BEACHPIRATININGA-NITERÓI-RJ}

\author{
Saulo Cezar Guimarães Farias \\ Universidade do Estado do Rio de Janeiro \\ saulocg@bol.com.br
}

\begin{abstract}
RESUMO
O estágio final das atividades produtivas e consumistas de uma sociedade é a geração de grande quantidade de material de descarte, superior a capacidade da natureza e desta sociedade de eliminá-lo e/ou reutilizá-lo.A produção excessiva de lixo na contemporaneidade compromete o equlíbrio dos ambientes naturais do planeta e a qualidade de vida dos seres que neles sobrevivem. Este trabalho apresenta uma crítica pautada nos conceitos de vulnerabilidades socioambientais das ciências ambientais aos resultados obtidos na coleta de material, observação e pesquisa de campo realizado em um período sazonal e estacionalentre os anos de 2002 e 2003, que teve como objetivo monitorar a poluição, deslocamento e deposição de lixo na praia de Piratininga, NiteróiRJ. Os resultados indicaram que a região é poluída por diversos agentes antrópicos, diretos e indiretos, incidindo descontinuamente e de maneira desigual por toda extensão da praia. Foram observados pelo menos quatro grandes agentes poluidores:as correntes marinhas, os turistas, o comércio local e a ação das ressacas sobre ocalçadão,desmontado-o.A pesquisa aponta para a importância de ações coordenadas entre o poder público, sociedade e iniciativa privada para diminuir a poluição na região e para uma conscientização dos problemas que o lixo causa na praia de Piratininga e nos ambientescosteiros do país.
\end{abstract}

Palavras-chave: Poluição; Ambientes costeiros; Lixo

\begin{abstract}
The final stage of the productive and consumptive activities of a society is the generation of large amount of discard material, exceeding the capacity of this nature and to eliminate it and / or reuse it society. Excessive production of waste in contemporary compromises the healthy balance of natural environments on the planet and the quality of life of beings who survive them. This paper presents a review guided by the concepts of social and environmental vulnerabilities of the results obtained in environmental sample collection, observation and field research conducted on aannual and seasonal period between the years 2002 and 2003 sciences, which aimed to monitor pollution displacement and deposition of waste in Piratininga beach, Niterói-RJ. The results indicated that the region is polluted by various indirect anthropogenic agents, direct and focusing discontinuously and unevenly throughout expanse of beach. Marine currents, tourists, local businesses and the action of storm surges on the boardwalk, disassembled
\end{abstract}


it: at least four major pollutants were observed. The research points to the importance of coordinated actions between government, society and the private sector to reduce pollution in the region and an awareness of the problems that the garbage issue in Piratininga beach and coastal environments of the country.

Keywords: Pollution.Coastal environments.Garbage.

\section{Introdução}

Desde os primórdios da existência dos seres humanos na superfície do planeta, exercendo suas atividades cotidianas, antes de subsistência e posteriormente na transformação intensa dos recursos em produtos e energia, os ambientes naturais eram afetados.

Contudo, havia tempo e espaço disponíveis para que o dano fosse regenerado e a paisagem permanecia inalterada, ou com alterações pouco significativas.

O climax e a aceleração da utilização dos recursos naturais pelas sociedades no século XX, em especial a exploração e produção de hidrocarbonetos, precipitou o surgimento de diversos desequlíbrios ambientais sentidos de maneira direta em todos os continentes.

Alguns ambientes se tonaram mais suscetíveis às ações humanas como a atmosfera e os recursos hídricos. Estes ambientes também são os mais delicados e sensíveis, e o resultado do seu desequilíbrio pode ser a condição para a piora da qualidade de vida da população e da extinção de diversas formas de vida, animais e vegetais.

O Brasil é um dos países mais afetados pela degradação ambiental marinha por possuir um extenso litoral, recortado por baias, ínstimos, ilhas, cabos e uma grande diversidade natural de fauna e flora costeira (AB'SABER, 2001; MORE, 2002).

A costa brasileira corresponde a 5\% do território nacional; abrange 512 municípios e é povoada por aproximadamente 39 milhões de habitantes.

O turismo nas cidades litorâneas do país tem aumentado significativamente nos últimos anos em decorrência da estabilidade da economia e do aumento do poder de compra da população. Esse aumento ocorre principalmente nos períodos de férias escolares em janeiro, fevereiro e julho movimentando o comércio local e a arrecadação municipal.

Geo UERJ. Rio de Janeiro - Ano 16, nº. 25, v.2, $2^{\circ}$ semestre de 2014, pp.276-296

ISSN: 1415-7543 E-ISSN: 1981-9021

http://www.e-publicacoes.uerj.br/index.php/geouerj 
Entretanto, o turismo promove efeitos negativos que se agravam quando o poder público não fornece infraestrutura para receber o contingente que chega nas cidades,nem fiscaliza o cumprimento de Leis criadas para este fim. As responsabilidades pela gestão dos resíduos originados pelo turismo no litoral temque ser compartilhadas entre a iniciativa privada, sociedade civil e poder público, situação que não é recorrente na maior parte dos municípios litorâneos brasileiros (CAMARGO, 2011).

O lixo deixado nas praias é responsável pela diminuição da vinda de turistas. Ao finaldas temporadas de grande movimento, vários tipos de lixo de difícil degradação como copos de plástico, canudos, garrafas são deixados nas regiões costeiras. O lixo não só diminui a qualidade de vida da população, mas também põe em perigo a vida dos organismos marinhos, como os mamíferos e aves marinhas (COE, 1997; FOWLER, 1987; LAIST, 1987; CARR, 1987; MORE, 2002; SILVA, 2009).

A região costeira do país tem sido intensamente ocupada desde a sua colonização. A especulação imobiliária é apontada como principal responsável pela destruição dos ambientes costeiros e essa disputa é mais acirrada nos estados da região sudeste, em especial, no litoral do estado do Rio de Janeiro.

Entre as cidades que compõea região metropolitana e que possui litoral muito valorizado por suas belas paisagens está Niterói.

O município é banhado por águas oceânicas e pelas águas da Baía da Guanabara e muito suscetível a diversas formas de poluição em suas praias (região compreendida da faixa de restinga até a zona de arrebentação próxima à água). A poluição das praias do município se dá de maneira descontínua e desigual, levando-se em conta os diversos fatores que proporcionam o acúmulo/deposição do lixo classificados, aqui neste estudo, como sólido (produzido e acumulado na praia por agentes antrópicos e físicos) e lixo flutuante (trazidos à praia pelas correntes marinhas e ventos).

Entre as praias oceânicas mais atingidas pela poluição está a de Piratininga, a maior praia do município com aproximadamente três quilômetros de extensão e muitas particularidades (localização, características físicas) que determinaram a sua escolha para análise.

Este trabalho apresenta uma crítica aos resultados colhidos durante a investigação/monitoramento de lixo na praia de Piratininga no município de Niterói-RJ 
no decorrer dos anos de 2002 e 2003, usando como estratégias metodológicas a pesquisa de campo, observação, análise documental e concluindo com uma análise crítica dos resultados a luz da categoria vulnerabilidades das ciências ambientais.

\section{História da produção legal sobre o ambiente marinho}

A criação da legislação de preservação dos ambientes marinhos sucedeu as determinações das principais conferências de meio ambiente da segunda metade do século XX.

Em 1974, apenas dois anos após a Conferência de Estocolmo sobre Meio Ambiente Humano, as Nações Unidas, foi lançado o Programa dos Mares Regionais para coordenar a implementação de uma série de planos e suportes legais para estabelecimento de acordos regionais obrigatórios entre Estados, com o fim de preservação do meio ambiente marinho (MORE, 2002).

A discussão sobre o tema era tão importante que mais de 120 países participaram da ação. Neste encontro foram estabelecidos 9 planos de ação abrangendo o Mar Mediterrâneo (1975), o Mar Vermelho e Golfo de Aden (1976), o Golfo Pérsico e Arábico (1978), o Largo Caribe (1981), os Mares do Leste Asiático (1981), o Pacífico Sudoeste (1981), o Africano Oeste e Central (1981), o Pacífico Sul (1982) e o África Oriental (1985) (MORE, 2002).

Neste encontro foram definidos 3 componentes básicos que seguiam a orientação adotada para ação ambiental na Conferência de Estocolmo de 1972: a) avaliação ambiental; $b$ ) gerenciamento ambiental e; $c$ ) medidas de suporte (MORE, 2002).

De acordo com Pedro (2012) a matéria tratada na Convenção sobre o Direito do Mar, realizada em MontegoBay, na Jamaica, veio integrar o arcabouço legislativo interno do Brasil em 1995, através do decreto nº1530 de 22.6.1995. A partir de então instituiu-sea Zona Econômica Exclusiva (ZEE) que delimitaria o mar territorial do país a 12 milhas náuticas, medidas a partir da linha de base prevista no Tratado, onde o país tem exclusividade para aproveitamento de recursos naturais, proteção ambiental, pesquisa científica e instalação de plataformas (PEDRO, 2012).

Em seu artigo 225, a Constituição Federal de 1988 determina que a proteção ambiental é dever de todos, sejam governo ou sociedade civil; outorga ao meio ambiente,status jurídico de bem de uso comum do povo, a ser preservado em prol da Geo UERJ. Rio de Janeiro - Ano 16, no. 25, v.2, $2^{\circ}$ semestre de 2014, pp.276-296 ISSN: 1415-7543 E-ISSN: 1981-9021 
qualidade de vida das presentes e futuras gerações (BRASIL, 2000). O mesmo artigo, em seu parágrafo $4^{\circ}$, declara como patrimônio nacional, entre outros ecossistemas, a zona costeira. Sua utilização deve ser feita, na forma da lei, em condições que assegurem a preservação do meio ambiente, inclusive quanto ao uso dos recursos naturais (BRASIL, 2000; MMA, 2010; PEDRO, 2012).

O Brasil tem $7.408 \mathrm{~km}$ de extensão de linha de costa e cerca de $442 \mathrm{mil} \mathrm{km}{ }^{2} \mathrm{de}$ zonas costeiras. Cinco das nove maiores regiões metropolitanas brasileiras situam-se à beira-mar. Na verdade, metade da população brasileira reside a não menos que $200 \mathrm{~km}$ do mar. O fato de a maior parte da população não dispor de redes de esgotos, nem de sistema de coleta de lixo, agrava os efeitos ambientais dessa concentração(ARAÚJO \& COSTA, 2003; MMA, 2010).

Araújo \& Costa (2003) observam que um grande número de pessoas não exerce os princípios básicos de cidadania e trata o espaço público como um bem que não lhe pertence, ignorando sua responsabilidade de mantê-lo limpo.

Os 70 milhões de habitantes das áreas costeiras geram 56 mil toneladas diárias de lixo, (das quais 42 nela) e em seguida ao ambiente costeiro.Estima-se que, em escala global, até $80 \%$ do lixo encontrado em praias chega à costa através dos rios próximos, dependendo dos padrões de circulação das águas costeiras. Os freqüentadores das praias também contribuem, às vezes de forma alarmante, ao deixar os próprios resíduos na areia (LAIST, 1987). A dinâmica costeira (ventos, ondas e marés) transfere o lixo para a água, tornando sua coleta muito mais difícil.

A pesca, a navegação e outras atividades marítimas, embora em menor escala, também têm sua parcela de culpa na poluição.

\section{O lixo nos ambientes costeiros}

Existem muitos conceitos sobre poluição, todos eles estão diretamente ligados aos de "estranheza", "desequilíbrio", "concentração", sendo assim, "só polui aquilo que é estranho ao ambiente, que o desequilibra por se apresentar em concentrações excessivas” (MAHLER, et al., 2002). Quando há um desequilíbrio, causado por acúmulo de elementos estranhos, de forma que modifique o ambiente o afastando dos padrões iniciais ou de padrões desejáveis, diz-se que há poluição. 
Fonte de riquezas supostamente inesgotáveis, os oceanos cobrem dois terços da superfície terrestre e, há muito tempo, servem de depósito para todo tipo de resíduos produzidos pelo homem, desde efluentes líquidos sanitários ou industriais até as mais diversas classes de lixo, como plásticos, vidros e materiais radioativos ou tóxicos. "Muitas pessoas, infelizmente, mantêm a falsa idéia de que os oceanos têm ilimitada capacidade de assimilar sem riscos o imenso e contínuo aporte de poluentes e lixo" (ARAÚJO \& COSTA, 2003 p. 64).

O atual estilo de vida das sociedades é o principal responsável pela crescente degradação dos oceanos. Enquanto a natureza é eficiente na reciclagem de seus resíduos, o homem continua acumulando o lixo (ARAÚJO \& COSTA, 2003; AMADOR, 1997).

No Brasil, nos últimos anos, "a produção média diária de lixo aumentou de 0,5 para 1,2 kg por pessoa nas capitais, e o consumo de embalagens de alimentos cresceu mais de 100\%". Quanto mais desenvolvido um país, "maior a geração de resíduos sólidos, em especial de derivados de petróleo como plásticos, nylon e isopor, de difícil degradação natural”. O rápido aumentoda produção de materiais sintéticos persistentes mudou significativamente o tipo e a quantidade de lixo gerados (ARAÚJO \& COSTA, 2003 p. 64).

Como a área afetada é extensa, é cada vez mais difícil evitar, ou minimizar, os efeitos desse tipo de poluição nos ecossistemas marinhos (ARAÚJO \& COSTA, 2003).

“O culto ao 'descartável', pilar da praticidade nas sociedades modernas, tem cobrado um custo ambiental alto [...]. "Retirar o lixo dos ambientes onde ele se acumula exige tempo, energia e espaço, logo, muito dinheiro". Esse custo tem levado a reflexões: nunca se falou tanto em lixo, coleta seletiva, reciclagem, lixões e aterros como nos últimos anos"(ARAÚJO \& COSTA, 2003 p. 64).

O lixo marinho resulta de lançamento proposital, manipulação ou eliminação descuidada, e muitas vezes tem origem em locais distantes da costa. Entre os fatores que influenciam sua produção estão o número de habitantes no território, seu nível educacional e poder aquisitivo e a área de produção, além da freqüência e eficiência do sistema de coleta (LAIST, 1987).

A maior parte da população mundial vive em zonas costeiras, a até $100 \mathrm{~km}$ da costa, e a tendência é o aumento dessa concentração demográfica.Com isso, cresce 
nessas áreas o volume de lixo e, em conseqüência, aumenta o descarte inadequado de materiais como embalagens plásticas, devido à ineficiência dos sistemas de coleta municipais e à baixa taxa de reaproveitamento e reciclagem. Os resíduos chegam facilmente à rede hidrográfica (levados por ventos e enxurradas ou lançados diretamente controlem a poluição marinha e os responsabiliza por danos decorrentes da violação dessas obrigações). No entanto, a questão do gerenciamento dos resíduos sólidos, em terra ou no mar, ainda é um desafio mundial.

Em ecossistemas naturais, inclusive nas praias, o lixo orgânico é reciclado por organismos decompositores existentes no solo, porém nas cidades, que são grandes produtoras de lixo, não ocorre esta reciclagem natural. "O lixo urbano acumulado causa poluição alimentar, da água, do ar, e principalmente do solo, e afeta a saúde humana por contato direto e indireto, pela proliferação de vetores ou transmissores de doenças, roedores, insetos, etc" (MONTEIRO, 2006 p. 23).

O descaso pela conservação dos ambientes costeiros é um tema muito estudado devidoaosseus efeitos nocivos para o ser humano e, em particular, nas praias brasileiras que são regiões de grande circulação de pessoas. A população é desinformada quanto à quantidade e tipos de poluição que acometem as praias.

\section{Orientação geográfica, histórico de ocupação e caracterização da praia}

No litoral do Rio de Janeiro existem muitas praias que sofrem com a poluição. A maioria delas está na região metropolitana banhadas pelas águas da Baía da Guanabara ou na costa oceânica onde desembocam rios muito poluídos. Também sofrem com a falta de estrutura para o reclhimento de esgoto e lixo, com os aterros e até com a invasão das áreas de restinga para construção de casas, hotéis entre vários tipos de construções.

O município de Niterói faz parte da região metropoliana do Rio de Janeiro e suas praias sofrem com os mesmos problemas que as praias do município vizinho. Como também é banhado pelas águas da Baia da Guanabara, recebe efluentes, lixo flutuante e demais tipos de poluentes em grande quantidade. As suas praias oceânicas também sofrem com a falta de saneaento básico e com a especulação imobiliária, além de receberem lixo do turismo. 
Ainda na região oceânica são quatro as principais praias com maior adensamento populacional e mais procuradas pelosturistas: Piratininga, Itaipú, Camboinhas e Itacoatiara.

A primeira delas tem uma peculiaridade em relação às demais, sua proximidade com a Baía da Guanabara, acabando por se tornar depósito de todos os tipos de lixo e poluentes. Essa proximidade tem grande influência negativa, pois o maior parte do lixo flutuante acaba sendo depositado pelas correntes em Piratininga.

Piratininga localiza-se no entorno da lagoa de mesmo nome, entre o Oceano Atlântico, a Serra Grande e o Morro da Viração, limitando-se com Itaipu, Cafubá, Camboinhas, Jacaré, São Francisco e Charitas e Jurujuba. O bairro, originado em parte da sesmaria doada a Cristóvão Monteiro, tinha na pesca a sua atividade mais marcante, tendo inclusive sediado uma colônia de pescadores na localidade conhecida como Tibau.

Com o surgimento das grandes fazendas na Região, como a denominada Piratininga, pertencente a Manuel de Frias e Vasconcelos, a área passa a produzir açúcar, aguardente e café, além de culturas de subsistência. Essa produção seguia, por terra ou mar, até a enseada de Jurujuba (BRASIL. CECITEC, 1996). Com o passar do tempo o interesse pela área torna-se crescente e, a partir dos anos 60, vários loteamentos irão surgir.

Durante o processo de nova configuração espacial do bairro, os posseiros sempre tiveram presença marcante sendo até hoje motivo de impasse, envolvendo as empresas imobiliárias, proprietários e o poder público (BRASIL. CECITEC, 1996). A área ao redor da lagoa de Piratininga é a de maior conflito e também a que reúne o maior contingente de população de baixa renda. Desde a década de 70 o bairro vem sendo ocupado por população de classe média, em virtude da melhoria das vias de acesso e da beleza do lugar: a praia, a lagoa, as ilhas, os costões e vegetação de restinga. Essa rápida ocupação já acabou com o extenso areal, as pitangueiras e os coqueiros que existiam (BRASIL. CECITEC, 1996).

Destaca-se ainda em seus limites a praia e o Forte de Imbuí, cuja entrada principal dá-se através do bairro de Jurujuba e que fazia parte do sistema de defesa da entrada da Baía da Guanabara. Conforme dados obtidos através do Censo do IBGE/1991, o bairro de Piratininga tem registrado nas últimas décadas uma das maiores taxas médias de 
crescimento populacional de todo o município. As taxas registradas nos períodos 70/80 e 80/91 foram consideravelmente superiores à média do município para os mesmos períodos (BRASIL. CECITEC, 1996).

Na década de 70 a taxa média de crescimento de Piratininga esteve por volta de $4,83 \%$, o que representava o $14^{\circ}$ maior crescimento entre os bairros de Niterói, enquanto o município em sua totalidade registrava $2,55 \%$. Já no período $80 / 91$ o bairro obteve uma aceleração no crescimento se comparado ao período anterior, marcando a taxa de $11,08 \%$ passando a ser o $3^{\circ}$ maior crescimento entre os bairros (BRASIL, 1991). O crescimento deste período é ainda mais significativo quando comparado à taxa média do município, que foi de $0,85 \%$. O bairro de Piratininga apresenta um total de 9.268 habitantes, o que corresponde a 2,12\% do total do município (BRASIL, 2010).

Piratininga é a mais extensa da Região Oceânica de Niterói, com aproximadamente três quilômetros de comprimento e dividida em duas por rochas. $\mathrm{Na}$ Prainha o mar é tranqüilo e existem concentrações rochosas de gnaise nas suas extremidades, como a Pedra da Baleia. Na faixa mais extensa de areia "Praião" o mar é mais agitado e a areia tem uma granulometria mais grossa devido ao intenso intemperismo físico (força das ondas) agindo nas rochas.

A área de estudo apresenta uma série de alinhamentos montanhosos, de direção SW/NE, concordantes com a estrutura geológica do litoral fluminense de formação précambriana. O embasamento cristalino é representado pela unidade cassorotibae gnaisse facoidal, composta por migmatito-diatexito com abundantes porfiroblastos de kfeldspato pouco deformados (cinza-claros), envoltos em matriz granoblástica, composta essencialmente de biotita, quartzo e plagioclásio, sob forma de rocha de granulação grossa (gnaisses) (FIGURA 1) (ROBSON, 2010). 


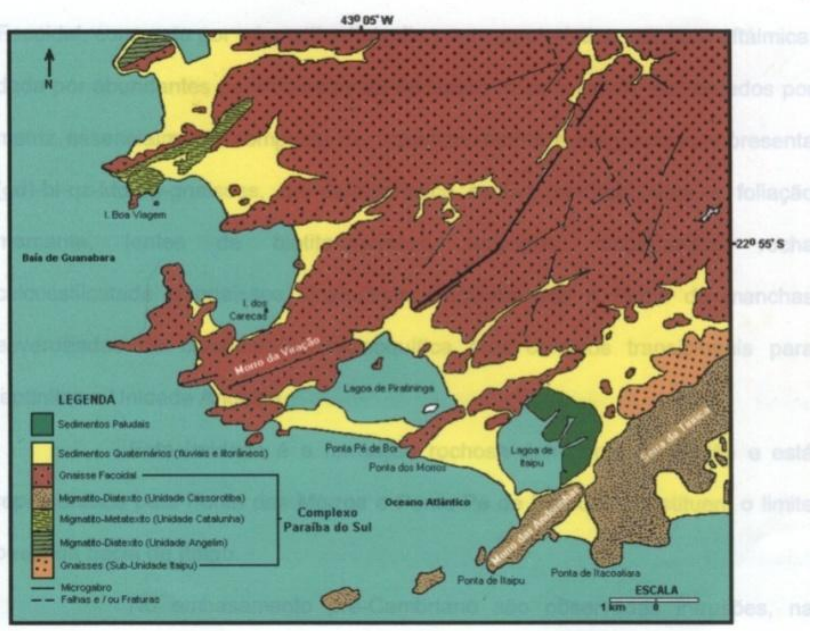

Figura 1: Mapa Geológico da folha Baía de Guanabara

Fonte: Base Cartográfica: DRM - Projeto Carta Geológica do Rio de Janeiro/ 1981.

A região também faz partedos depósitos praiais marinhos e lagunares. Estes depósitos carateristicamente ocorrem sob a forma de cordões arenosos ao longo do litoral oceânico, perfazendo toda a sequência de praias, dentre as quais se destacam: Macumba, Recreio dos

Bandeirantes, Bara da Tijuca, Joatinga, São Conrado, Leblon-Ipanema, Copacabana, a oeste da Baía de Guanabara, e Piratininga, Camboinhas, Itaquatiara e Itaipuaçu, do lado leste, em Niterói (VALERIANO, 2012).

\section{Materiais e Métodos}

Com o objetivo de caracterizar e monitorar o material antropogênico depositado na praia, seja ele pelas correntes ou pela ação do homem, foi empreendida uma pesquisa de campo. A análise do material coletado foi sistematizada eas informações obtidas,fornecerão dados para instituições públicas de conservação do meio ambiente, institutos de educação, instituições não governamentais e entidades particulares interessadas na resolução desta problemática que é o lixo em ambientes costeiros.

Para que a pesquisa oferecesse dados mais precisos e as incursões à campo para coleta ocorreram na parte da manhã, em diferentesdias da semana e condições climáticas diversas (sol forte no verão, outono, inverno e nublado na primavera) mostrando as variáveis de distribuição, concentração do lixo pela área de estudo 
(manhãs dos dias 18, 19 e 20 de dezembro de 2008, 11 e 12 de abril, 21 e 22 de julho e no dia 4 de outubro de 2009).

A coleta do lixo depositado na praia foi caracterizada utilizando-se a classificação de Willoughby (1986), mais utilizada pela literatura internacional, que divide o lixo em 7 categorias, e além destas, foram incluídas mais duas categorias devido a frequiência na praia, sendo as duas últimas, fragmentos de material de construção e madeira modificada e/ou envernizada.

(1) - Sacos plásticos;

(2) - Calçados;

(3) - Blocos de polyetileno;

(4) - Garrafas plásticas;

(5) - Latas de metal e containers;

(6) - Fragmentos de rede de pesca;

(7) - Lâmpadas;

(8) - Madeira modificada ou/e envernizadas;

(9) - Fragmentos de material de construção.

Assim sendo, a área de estudo foi separada nos seguintes locais de perfilagem, em função de sua extensão e dinâmica:

- Prainha, com aproximadamente 800 metros de extensão (FIGURA 2 e 4);

- Primeira parte da praia grande de aproximadamente 800 metros de extensão também (FIGURA 2 e 5);

- Segunda parte da praia grande com aproximadamente 700 metros (FIGURA 2 e 6); e a terceira parte com também aproximadamente 700 metros (FIGURA 2 e 6).

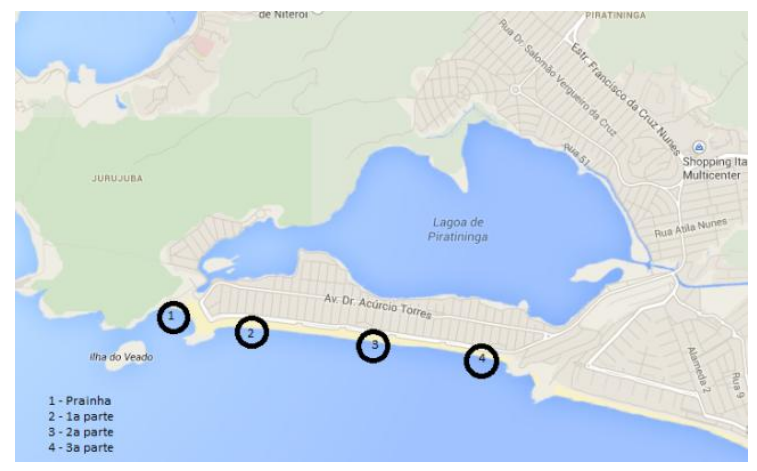

Figura 2: Mapa da divisão da praia 


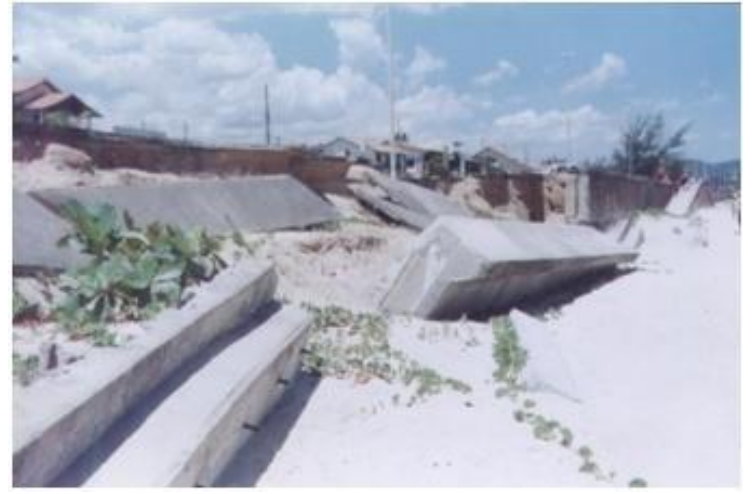

Figura 3: Calçadão destruído pela ressaca de junho de 1999

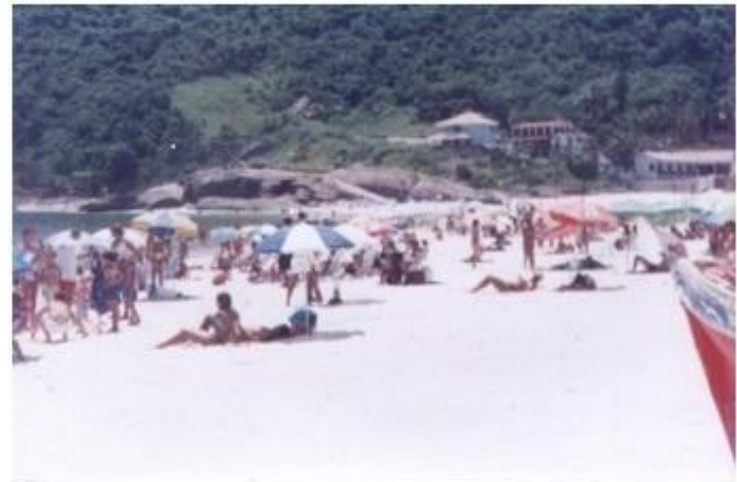

Figura 4: Enseada de mar calmo (Prainha)

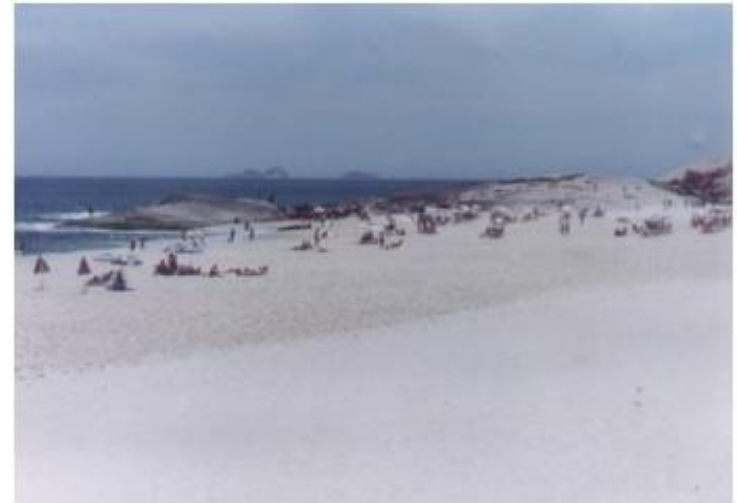

Figura 5: Praia grande da pedra da Galheta até 300 metros ( $1^{\mathrm{a}}$ parte $)$ 


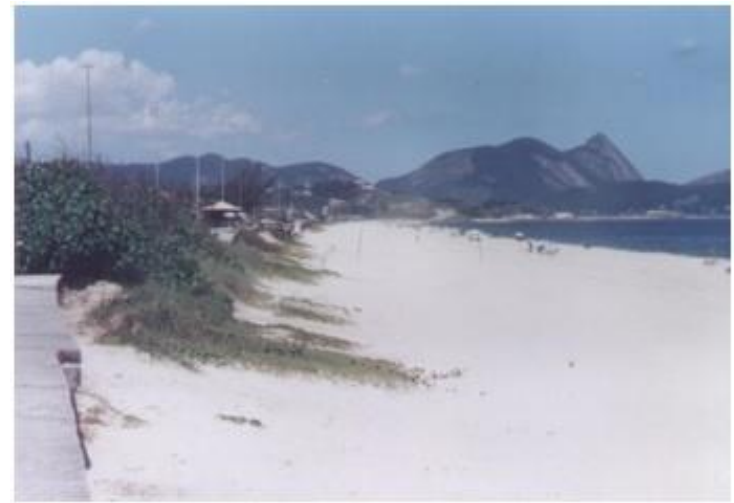

Figura 6: Praia grande a partir do trecho de 300 metros $\left(2^{\mathrm{a}}\right.$ e $3^{\mathrm{a}}$ parte $)$

\section{Discussão dos dados}

Todos os dados coletadosdurante a pesquisa mostram a concentração de diversos tipos de materiais (orgânicos e inorgânicos), depositados por agentes físicos e químicos descontinuamente e desconcentradamente na extensão da praia.

Os dados obtidos após um ano de observações nos levou à algumas conclusões:

- A dinâmica das marés e a direção do vento fazem com que o lixo seja depositado de maneira diferenciada nas partes da praia;

- Em situações de junção de fatores naturais como frentes frias, preamar e lua cheia faz com que o mar fique mais agitado (ressacas) e o lixo seja depositado em maior quantidade pela praia;

- O plástico, durante todos os meses do ano e em todas as partes da praia observada, é o material de maior quantidade seguido por materiais orgânicos.

Quanto maior a diversidade destes materiais maior é aquantidade de agentes poluidores que agem no local. Os quiosques do calçadãorecebem muitos banhistas e é onde se concentra grande parte do comércio de comidas e bebidas. A maior parte destes apresentam lixeiras, porém insuficientes para a quantidade de lixo (recipientes metálicos, canudos copos e garrafas plásticas, guardanapos e pacotes de papel e papelão) e resíduos orgânicos.

Os comerciantes donos dos quiosques são responsáveis por grande parte do lixo gerado e também deveriam zelar pelo patrimônio natural. É seu dever manter a área limpa e, com isso, eliminar o surgimento de vetores que surgem atraídos pelo lixo acumulado e esgotos em busca de comida. 
Outro fator causador de poluição é o desmontedo calçadão (FIGURA 3) durante as ressacas, deixando blocos de concreto espalhados pela praia, podendo causar acidentes com banhistas sendo também esconderijo de ratos, cobras e insetos.

A construção do calçadão interferiu com uma dinâmica da natureza penetrando pela faixa da restinga, por isso, em determinadas épocas do ano em que as ressacas são mais violentas, as ondas atingem o calçadão cavando a areia por baixo da armação de concreto acarretando o desmoronamento do mesmo, deixando espalhado pela praia fragmentos de material de construção e pedaços de isopor utilizado em sua construção.

Observamos que os pedaços de concreto espalhados pela areia causam acidentes como cortes nos pés e as cavidades no calçadão são esconderijos para ratos e insetos que trazem doenças como micoses e possivelmente leptospirose.

O isopor usado para a construção do calçadão foi um item abundante. É um material que se dispersa pela superfície da água e é facilmente confundido com pequenos peixes e organismos consumidos por aves e outros peixes. A ingestão destes materiais que não consegue ser digerido, causa no estômago a sensação de satisfação fazendo com que estes parem de se alimentar e até mesmo sufocando causando a morte (LAIST, 1987).

Com a poluição das praias do entorno da Baia da Guanabara, a procura pelas praias oceânicas de Niterói aumentou significativamente nos últimos dez anos originando uma demanda muito grande de turistas para estas regiões.

O lixo flutuante, por ser um aspecto visível da poluição das águas da Baía de Guanabara e conseqüentemente nas praias oceânicas, é o que mais chama a atenção.

O plástico tem sido o principal lixo observado, devido a sua baixa degradabilidade, vidros e objetos metálicos, assim como fragmentos de material de construção tem sido encontrados em apreciável quantidade. As conseqüências desta poluição, são consideráveis, e representa uma ameaça à saúde humana (COE, 1997; FOWLER, 1987; FERRINHO et al, 1991; LAIST, 1987).

Os materiais sintéticos e metálicos apresentam baixa degradabilidade e uma dispersão muito grande pela praia, dificultando a limpeza pela prefeitura, que faz recolhimentosemanal deste lixo pelos caminhões ou pelo "tatuzinho" (trator com uma espécie de peneira que revolve a areia retirando os resíduos maiores). 
Os turistas e frequentadores deixam na areia todo tipo de resíduo: matéria orgânica (comida), embalagens plásticas, e recipientes de metal que trazem de casa ou consomem no local.

É observado também que grande quantidade de linhas, redes e outros artefatos de pesca são perdidas no mar a cada dia, não só contaminando o ambiente, mas trazendo sérios riscos para peixes, aves, golfinhos e baleias. A eliminação irregular no mar do lixo produzido em navios agrava este quadro(LAIST, 1987). O lixo espalha-se rapidamente no mar, dependendo das condições oceanográficas, atingindo locais aparentemente improváveis, como praias desertas, ilhas oceânicas ou recifes costeiros.

Uma praia, transformada em depósito de lixo por turistas é capaz de absorver boa parte dos dejetos, mas devolve o excesso na mesma moeda, ou seja, restos de alimentos podem sofrer decomposição de modo a ser absorvidos pela areia, mas nas praias mais movimentadas os banhistas sempre conseguem sujar muito mais rápido do que a areia consegue absorver. (COE, 1997; FOWLER, 1987; FERRINHOet al, 199; LAIST, 1987). O lixo a beira mar e a proliferação de moscas causam diversos problemas na saúde do ser humano fora os riscos de cortes causados por vidros e latas de metal.

Entre os materiais mais encontrados estão canudos plásticos, que são difíceis de serem recolhidos e se espalham facilmente, sendo confundidos por peixes, aves e anfíbios com minhocas, enguias e outros organismo que fazem parte da alimentação dos mesmos.

Os materiais que bóiamtedem a ficar em suspensão na superfície do oceano por muito tempo, e aqueles que não flutuam, afundam e permanecem e permanecem no fundo do mar por anos e até décadas. Até recentemente, o problema de lixo plástico ou outros materiais sintéticos flutuantes no oceano era geralmente considerado menor, comparado com outros tipos de contaminantes.

Segundo Laist (1987) o mecanismo de impacto nas espécies marinhas sugere que os diretos são primariamente mecânicos. Mamíferos marinhos, pássaros marinhos, tartarugas e peixes tornam-se fisicamente embaraçados em linhas ou sacos plásticos flutuantes abertos, e ingerem pequenos pedaços de materiais sintéticos. Uma vez embaraçados, animais podem afundar, sofrer impactos na sua habilidade de caçar alimentos ou mesmo de evitar predadores, provocando feridas e infecções, através da 
ação abrasiva e cortantede alguns artefatos, ou apresentando um padrão de comportamento alterado, o que dificulta a sua sobrevivência.

Por último o lixo flutuante trazido pelas correntes, oriundo principalmente da Baia da Guanabara, fonte de poluição das praias oceânicas tanto do município do Rio de Janeiro quanto Niterói. Este lixo é composto de garrafas plásticas, copos, matéria orgânica, isopor e madeira modificada e as correntes os depositam nas regiões de praia com reentrâncias e baias (cantos).

Nas figuras (7, 8, 9 e 10) observa-se a grande concentração de materiais plásticos, principalmente nas estações verão e primavera e de material de construção, madeira modificada e isopor no outono e inverno, mostrando uma disposição quanto a variação climática para os mesmos.

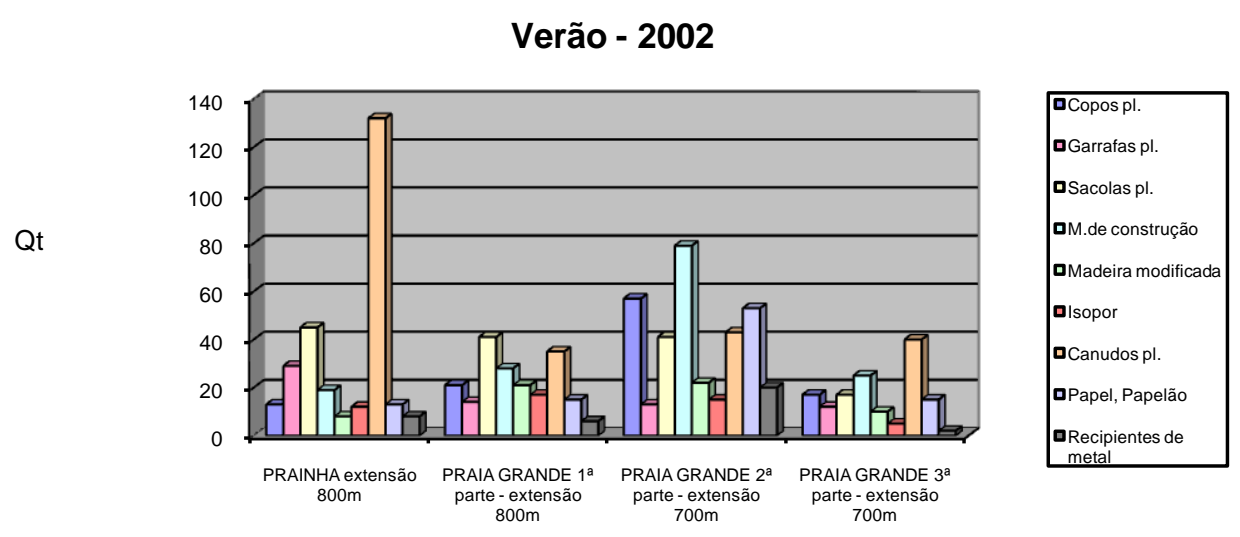

Figura 7: Gráfico da coleta no verão de 2002

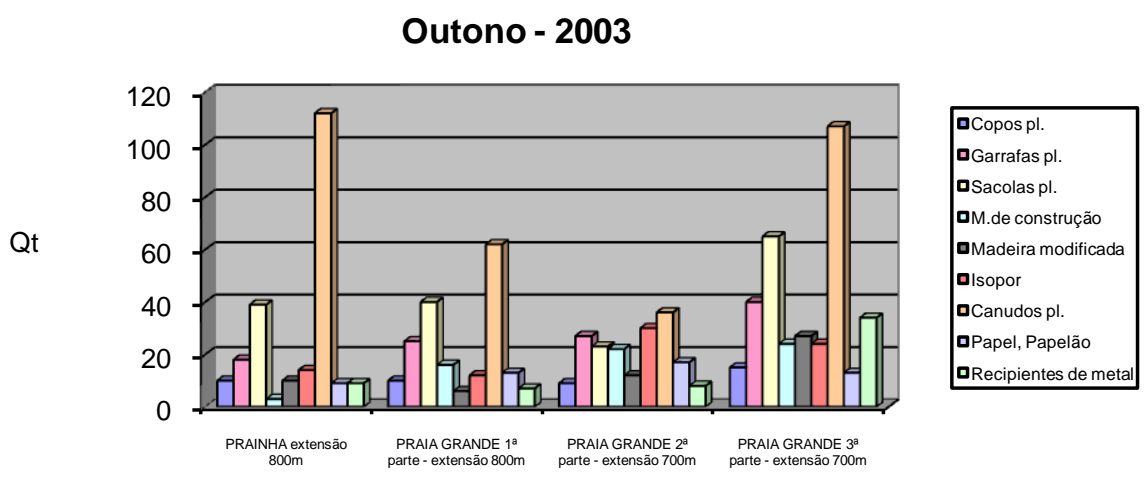

Figura 8: Gráfico da coleta dooutono de 2003. 


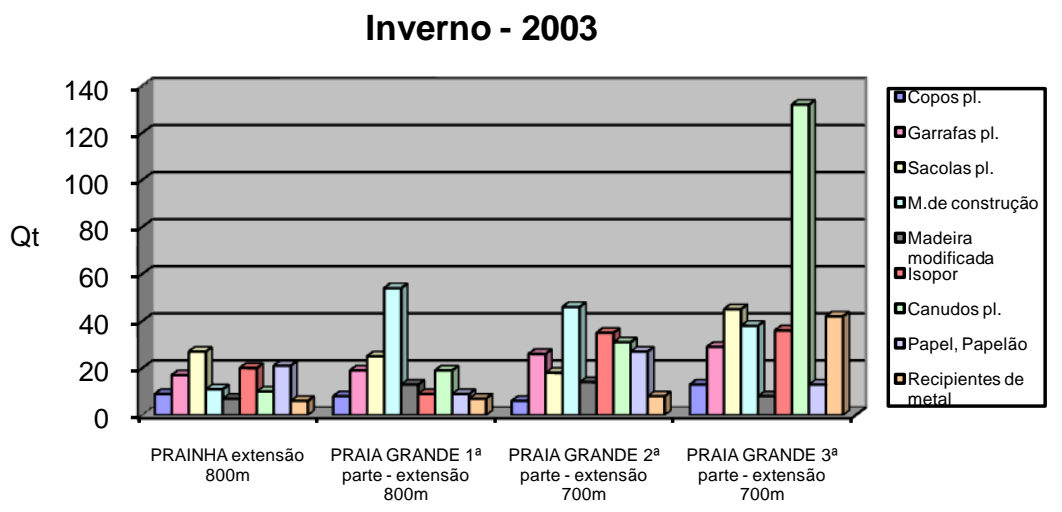

Figura 9: Gráfico da coleta do inverno de 2003

No inverno os ventos sopram mais fortes deixando as ondas mais fortes que, muitas vezes, resultam em ressacas violentas destruindo o calçadão e liberando muito material de construção pela areia. Os canudos plásticos são muito abundantes se espalhando facilmente sendo difíceis de serem recolhidos.

\section{Primavera - 2003}

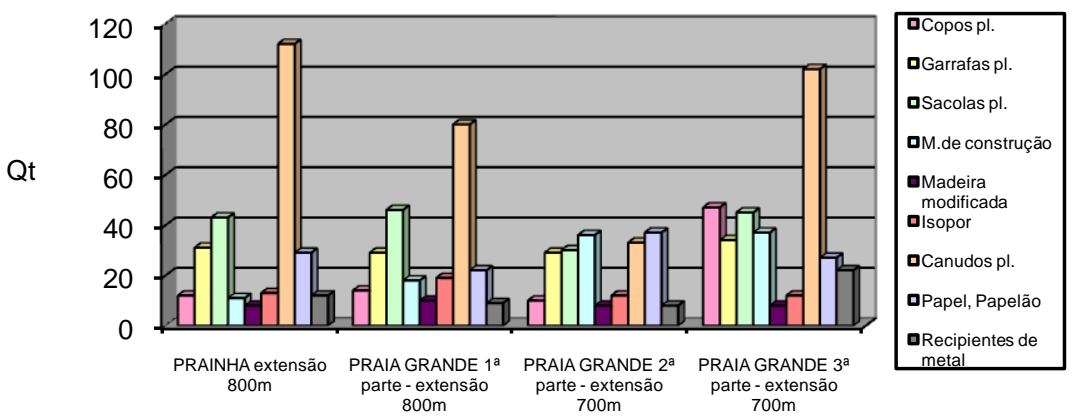

Figura 10: Gráfico da coleta da primavera de 2003

Assim como no verão o aumento da temperatura,carcterística da estação, faz com que a procura pelas praias aumente e consequentemente o lixo também. Vale lembrar que os períodos com maior concentração de pessoas nestas regiões estárelacionadaao verão, aos finais de semana e feriados.

\section{Considerações finais}

O tema "Poluição de ambientes costeiros por lixo" é retratado por inúmeras pesquisas no Brasil e no mundo e isso vem chamando a atenção dos pesquisadores desde a década de 1970, porém poucos dados existem sobre esse assunto na costa 
brasileira. O problema do lixo nos oceanos vinha sendo tratado como um problema estético ou como um problema isolado. O lixo atinge todas as classes sociais e não é um problema individual ou público é um problema social.

É observado que a poluição vem de vários agentes diretos e alguns indiretos dificultando apontar os culpados pela poluição desta praia que é fonte de atração turística e, conseqüentemente, de renda para a população local.

Foi encontrada grande variedade de lixo como: materiais plásticos, material de construção, isopor que trazem vários tipos de problemas para os seres humanos e aos organismos vivos da praia, os pedaços de concreto espalhados pela areia causam acidentes como cortes nos pés e as cavidades no calçadão são esconderijos para ratos e insetos que trazem doenças como micoses e possivelmente leptospirose.

Entre os materiais mais encontrados estão canudos plásticos, que são difíceis de serem recolhidos e se espalham facilmente, sendo confundidos por peixes, aves e anfíbios com minhocas, enguias e outros organismo que fazem parte da alimentação dos mesmos.

A maior parte da poluição pode ser evitada com um programa de informação ambiental para os turistas e população local e outros são mais difíceis de resolver no caso do calçadão e do lixo flutuante que é trazido para a praia.

A praia de Piratininga é a praia mais poluída das oceânicas e também a que possui menos estudos sobre o lixo produzido e trazido para ela. Devido essa falta de informação há uma grande necessidade de ampliar estas pesquisas.

Para se conseguir um melhor resultado na diminuição da poluição encontrada na praia de Piratininga seria necessário uma articulação entre os responsáveis públicos, iniciativa privada e sociedade civil articulada na criação, implementação e fiscalização de ações e projetos socioambientais e técnicos que permitam a natureza se recuperar de um estrago que vem sendo feito há décadas.

Projetos paliativos que só melhoram a aparência da região não só irão mascarar e esconder os problemas que a praia é acometida, mas também podem aumentar os danos ao ecossitema litorâneo. 


\section{Referências bibliográficas}

AB'SABER, A. N. Litoral do Brasil (Brazilian Coast). São Paulo: Metalivros, 2001. $288 \mathrm{p}$.

AMADOR, Elmo. A Baia da Guanabara e Ecossistema Periféricos: Homem e Natureza, Rio de Janeiro, 1997. pg. 21 - 539.

ARAÚJO, Maria Christina B.; COSTA, Mônica Ferreira. Lixo no ambiente marinho. Ciência Hoje - vol. 32, nº 191, março de 2003.

BRASIL. Constituição (1988). Constituição da República Federativa do Brasil. Organização de Alexandre de Moraes. 16.ed. São Paulo: Atlas, 2000.

BRASIL. CECITEC. Niterói em dados. Quadros comparativos, indicadores e índices. Prefeitura de Niterói, 1996. Niterói.

BRASIL. Fundação Instituto de Geografia e Estatística - IBGE, 1990-1991. Anuário Estatístico do Rio de Janeiro. Indicadores Demográficos.

BRASIL. Fundação Instituto de Geografia e Estatística - IBGE, 1991. CensoDemográfico. Rio de Janeiro: IBGE.

CAMARGO, Luan José Jorge etal.Análise da sustentabilidade do turismo ecológico no município de Bonito, Mato Grosso do Sul na promoção do desenvolvimento regional. Soc. nat. (Online) [online]. 2011, vol.23, n.1, pp. 65-75.

CARR, A. Impact of nondegradable marine debris on the ecology and survival outlook of sea turtles. Marine Pollution Bulletin 18, 1987, 352-356.

COE, J. M.; ROGERS, D. B. Marine Debris: Sources, Impacts, and Solutions. SpringerVerlag, New York, 1997, 432 pp.

FERRINHO, P. D. L.;BARRON, P. M.;BUCH, E.;GEAR, J. S. S.;MORRIS, A.;ORKIN, F. M.;BEKKER, S.;JEFRREY, A. (1991) Measuring environmental Healt status in Oukasie (Transvaal, South África). South African Medical Journal 79: 29-31.

FOWLER, C. W. Marine debris and Northem fur seals: a Case study. Mar pollut. Bull. 18, 1987.

LAIST, D. W. Overviwof the biological effects os lost and discarded plastic debris in the marine enviroment. Marine PollutionBulletin 18 6(B),1987, 319-326.

LAVENÈRE-WANDERLEY, A. A. O. Caracterização ambiental da lagoa de Itaipú através dos processos sedimentares em associação com a dinâmica atual. Dissertação ( Mestrado em Geologia e Geofísica Marinha). Universidade Federal Fluminense - UFF, 1999.

Geo UERJ. Rio de Janeiro - Ano 16, nº. 25, v.2, $2^{\circ}$ semestre de 2014, pp.276-296

ISSN: 1415-7543 E-ISSN: 1981-9021

http://www.e-publicacoes.uerj.br/index.php/geouerj 
MAHLER, C. F.; ARAÚJO, F.; PARANHOS, R.Poluição: poluição aquática e resíduos sólidos. Fundação Bio-Rio, Rio de Janeiro, RJ,2002.

MMA. PROBIO. Projeto de conservação e utilização sustentável da diversidade biológica. Relatório de Atividades, Probio 1996-2002. Brasília: MMA, 2002. 73 p.

MMA. Áreas prioritárias para a conservação, uso sustentável e repartição de benefícios da biodiversidade brasileira: atualização - Portaria MMA n. 9, de 23 de janeiro de 2007. 2.ed. Brasília: MMA/SBF, 2008. 328 p. (Série Biodiversidade, 31)

Gerência de biodiversidade aquática e recursos pesqueiros. Panorama da conservação dos ecossistemas costeiros e marinhos no Brasil. Brasília: MMA/SBF/GBA, 2010. 148 p.

MONTEIRO, Alessandra Elias. Índice de Qualidade de Aterros Industriais - IQRI. Dissertação (Mestrado em Engenharia Civil) - Universidade Federal do Rio de Janeiro, COPPE, 2006.

MORE, Rodrigo Fernandes. A poluição do meio ambiente marinho e o princípio da precaução - Página 2/4. Jus Navigandi, Teresina, ano 7, n. 58, 1 ago. 2002. Disponível em: <http://jus.com.br/artigos/3194>. Acesso em: 17 jul. 2014.

NECKES, Stjepan. The Protection and Development of the Marine Environment: UNEP'S Oceans and Coastal Areas Programme", in "Ocean Management in Global Change.Coleção de artigos sobre a "InternationalConferenceonOcean Management in Global Change" (Conferência de Colombo 92), realizada em Gênova, em 22-26 de julho de 1992.

PEDRO, Antonio Fernando Pinheiro. Direito do mar e gerenciamento da costa brasileira. Revista Ambiente Legal [online]. 2012. Disponível em:

http://www.ambientelegal.com.br/direito-do-mar-e-gerenciamento-da-costabrasileira/Acesso em: 23 jul. 2014.

ROBSON, Lucas Bartholomeu. Análise dos registros palinológicos costeiros quaternários na área da lagoa de Itaipu, Estado do Rio de Janeiro, Brasil.Tese (Doutorado em Geologia) - Universidade Federal do Rio de Janeiro, Instituto de Geociências, Programa de Pós graduação em Geologia, 2010.

SILVA, Iracema Reimãoetal.Diagnóstico ambiental e avaliação da capacidade de suporte das praias do bairro de Itapoã, Salvador, Bahia. Soc. nat. (Online) [online]. 2009, vol.21, n.1, pp. 71-84.

VALERIANO, Cláudio de Morissonet al.; SILVA, Luiz Carlos da (Org.).Geologia e recursos minerais da folha Baía de Guanabara SF.23-Z-B-IV, estado do Rio de Janeiro. Escala 1:100.000 / - Belo Horizonte: CPRM, 2012.

WILLIANS, A. \& Simmons, S. Estuarine Litter at the Estuarine Beach interface in the Bridtol Channel. Journal of Coastal Research 13 (4), 1997, 1159-1165. 
WILLOUGHBY, N. G. Man-made Litter on the Shores of the Thousand Island Archipelago, java. Resident Adviser, UNDIP/Newcastle Link, Fisheries Departament, UniversitasDiponegoro, J1 ImanBarjo, 1-3, Semarang, Central java, Indonésia. Marine Pollution Bulletin 17 (5), 1986, 224-2.

Artigo recebido para publicação em abril de 2014.

Artigo aceito para publicação em outubro de 2014. 